\title{
Media Sosial Ruang Dayak dalam Mereduksi Stigma Kebudayaan Dayak
}

\author{
Pricilla Pascadeany Frelians ${ }^{1}$, Yudi Perbawaningsih ${ }^{2}$ \\ ${ }^{1,2}$ Program Studi Magister Ilmu Komunikasi, Universitas Atma Jaya Yogyakarta \\ Jl. Babarsari No 6, Yogyakarta 55281 \\ Email: dheafrelians@gmail.com ${ }^{1 *}$; yudiperbawaningshi@yahoo.com² \\ *Corresponding Author
}

\begin{abstract}
Social media as a form of technological development provides an opportunity for the young Dayak generation to make communication and information media as a means of reducing the stigma attached to Dayak culture in the national and international community. This study aims to analyze the role of social media in reducing the stigma of Dayak culture. This research method is a qualitative explanative with the case study approach of the Dayak culture stigma. The data collection technique used in-depth interviews with the founder of social media Ruang Dayak and four followers on Instagram, Facebook, and Twitter as a source of data triangulation. The results showed that the stigma in Dayak culture was included in the types of stigma in the form of prejudice, stereotypes, and labels. This stigma arises because of a lack of knowledge and information about the Dayak culture. The dissemination of information in new media and quickly making social media with cultural content plays a role in reducing cultural stigma by optimizing an educational approach through information dissemination. Providing sufficient and reliable information can overcome the problem of the emergence of cultural stigma. This research contributes in the form of recommendations to Ruang Dayak account managers to optimize the educational approach through social media in reducing cultural stigma.
\end{abstract}

Keywords: Cultural Stigma; Dayak; Social Media

\begin{abstract}
Abstrak
Media sosial sebagai bentuk perkembangan teknologi memberi peluang bagi generasi muda Dayak untuk menjadikan media komunikasi dan informasi tersebut sebagai sarana mereduksi stigma yang melekat pada kebudayaan Dayak di kalangan masyarakat nasional maupun internasional. Penelitian ini bertujuan untuk menganalisis peran media sosial dalam mereduksi stigma kebudayaan Dayak. Metode penelitian ini yaitu eksplanatif kualitatif dengan pendekatan studi kasus Stigma budaya Dayak. Teknik pengumpulan data menggunakan teknik wawancara mendalam dengan pihak founder media sosial Ruang Dayak serta followers di Instagram, Facebook, dan Twitter yang berjumlah empat orang sebagai sumber triangulasi data. Hasil penelitian menunjukkan bahwa stigma pada kebudayaan Dayak termasuk pada jenis stigma berupa prasangka, stereotip, dan label. Stigma tersebut muncul karena kurangnya pengetahuan dan informasi tentang kebudayaan Dayak. Persebaran informasi di new media dan cepat menjadikan media sosial berkonten kebudayaan berperan dalam mereduksi stigma kebudayaan dengan mengoptimalkan pendekatan pendidikan lewat persebaran informasi. Pemberian informasi yang cukup dan dapat dipercaya mampu mengatasi masalah munculnya suatu stigma kebudayaan. Penelitian ini memberikan kontribusi berupa rekomendasi kepada pengelola akun Ruang Dayak untuk mengoptimalkan pendekatan pendidikan melalui media sosial dalam mereduksi stigma kebudayaan.

Kata kunci: Stigma Kebudayaan; Dayak; Media Sosial
\end{abstract}

\section{Pendahuluan}

Globalisasi telah merasuk ke seluruh wilayah dan aspek kehidupan manusia di dunia. Mulai dari aspek ekonomi, politik, teknologi bahkan interaksi kultural yang mencakup standarisasi, komunikasi, transportasi, perdagangan dan imigrasi semua bersinggungan dengan globalisasi (Bhatasara, 2015). Globalisasi menjadi salah satu pengaruh terkikisnya kebudayaan lokal. Globalisasi turut memunculkan perkembangan teknologi memiliki beberapa dampak positif. Leburnya batas antarnegara dan kemajuan teknologi yang semakin pesat menjadikan persebaran arus informasi kebudayaan antarnegara menjadi lancar dan mudah diakses di mana saja dan kapan saja. Informasi terkait budaya dapat diperoleh secara sadar oleh masyarakat yang mencari tahu tentang kebudayaan suatu negara atau daerah dan juga diperoleh secara tidak sadar lewat informasi yang terselip konten budaya dalam bentuk musik, film, iklan, dan artikel. 
Indonesia dikenal sebagai negara multikultural memiliki beragam kebudayaan. Menurut berita detik news, Jokowi dalam pidatonya di Taman Pujaan Bangsa, Candi Margarana, Tabanan, Bali pada pembagian sertifikat tanahbulanFebruari2018, menyebutkan bahwa Indonesia memiliki 714 suku dengan lebih dari 1.100 bahasa daerah yang berbedabeda dan beragam (Prasetia, 2018). Salah satu suku yang ada di Indonesia adalah suku Dayak. Dayak merupakan sebutan bagi penduduk "asli" pulau Kalimantan yang terdiri dari enam suku besar dan 405 sub suku yang tersebar di seluruh wilayah pulau Kalimantan (Darmadi, 2016). Menurut portal berita online IDNtimes, suku Dayak dikenal dengan totem atau patung pahatan yang eksotis, keramahan dalam menyambut tamu, asrinya lingkungan yang dijaga masyarakat Dayak, kecantikan para gadis Dayak, sikap menghargai leluhur dan menjaga benda-benda pusaka dan mandau yang menjadi senjata tradisional masyarakat Dayak (Anggraeni, 2018).

Selain kebudayaan dan adat istiadatnya, hingga kini Dayak masih lekat dengan stigmastigma. Stigma merupakan bentuk prasangka yang mendiskreditkan atau menolak seseorang atau kelompok karena dianggap berbeda dengan diri atau kebanyakan orang (Maharani, 2017). Informasi kompas.com, terdapat stigma tentang perayaan Gawai Dayak yang identik dengan mabuk-mabukan (Irawan, 2016). Stigma lainnya adalah bahwa masyarakat Dayak merupakan pembakar atau pembalak hutan yang berkaitan dengan aktivitas berladang masyarakat Dayak (Pradana, 2017). Stigma yang melekat pada kaum wanita Dayak yaitu bahwa gadis Dayak memiliki sifat defensif yang sangat tidak beralasan serta berpikiran sempit dan memiliki kekuatan magis yang kuat hingga dapat menghilangkan alat vital pasangannya (Gieskha, 2018). Tulisan yang berjudul "The Dayak: Close to the Eyes, Far from the Heart" dipaparkan mengenai stigma tentang Dayak yang barbar terkait dengan mengayau, tinggal di pedalaman hutan serta berpindah-pindah tempat dan masih mengumpulkan makanan atau berburu untuk bertahan hidup (Nasrullah, 2017). Stigma ini kerap kali menjadikan kebudayaan Dayak yang indah dan telah berkembang tetap kurang dikenal masyarakat.

Perkembangan teknologi yang dihasilkan oleh globalisasi dilihat sebagai peluang untuk mengenalkan tentang kebudayaan Dayak pada khalayak luas. Media sosial menjadi salah satu sarana yang digunakan oleh para generasi muda Dayak untuk menyebarkan informasi tentang kebudayaan Dayak baik di tataran nasional maupun internasional. Media sosial hingga kini menjadi salah satu media promosi yang cukup efektif. Tahun 2015 saja We Are Social melaporkan pengguna aktifmedia sosial sekarang sudah mencapai 2,2 milyar dari total populasi 7,3 milyar (K. D. Utami, 2016). We Are Social melaporkan pada tahun 2018 sebanyak $71 \%$ dari responden yang adalah masyarakat Indonesia memiliki sikap percaya bahwa teknologi menawarkan lebih banyak peluang daripada resiko. Survei tersebut menunjukkan bahwa masyarakat Indonesia memiliki sikap positif terhadap peran teknologi digital. Dampak positif dari perkembangan teknologi juga dirasakan dalam aspek kebudayaan (Hootsuite, 2018).

Salah satu akun media sosial milik generasi muda Dayak yang memberikan informasi seputar kebudayaan Dayak adalah "Ruang Dayak". "Ruang Dayak" dibentuk oleh salah seorang mahasiswa asal Kalimantan yang berada di Yogyakarta bernama Marselinus Dwi Purnama pada tahun 2015. "Ruang Dayak" awalnya dibentuk berlandaskan pada founder dan rekanrekannya sesama Dayak yang merasa bahwa budaya Dayak tidak dikenal oleh banyak orang dan masih minimnya informasi tentang Dayak yang dapat diakes oleh masyarakat lainnya. "Ruang Dayak" mencoba memberikan informasi tentang kebudayaan Dayak yang kini sudah semakin beradaptasi dengan perkembangan zaman. 
Adanya media sosial sebagai bentuk dari perkembangan teknologi memberi harapan bagi generasi muda Dayak untuk mereduksi stigma yang melekat pada kebudayaan Dayak di kalangan masyarakat baik pada tataran nasional maupun internasional. Berdasarkan penjabaran tersebut, penelitian ini mengenai peran media sosial "Ruang Dayak" dalam mereduksi stigma kebudayaan Dayak sebagai salah satu akun media sosial. Akun media sosial ini merupakan akun dengan followers yang cukup banyak yang mengunggah konten mengenai kebudayaan Dayak dalam konotasi positif atau tidak memperkuat stigma tentang kebudayaan Dayak yang ada di masyarakat.

Peran media sosial dan kaitannya dengan stigma sebelumnya telah diulas oleh beberapa praktisi dan akademisi. Betton et al. (2015) beserta keempat rekannya meneliti tentang peran media sosial Twitter dalam mereduksi stigma dan diskriminasi pada penderita kesehatan mental yang buruk di Inggris. Hasil penelitian tersebut menunjukkan bahwa lewat media sosial kisah-kisah dan aspirasi yang bersifat pribadi terkait dengan kesehatan mental yang kerap tidak terdengar dapat menjadi konsumsi publik dan dibagikan tanpa hambatan temporal dan spasial. Media sosial memiliki potensi untuk memengaruhi, sikap publik, media mainstream dan kebijakan (Betton et al., 2015).

Penelitian serupa lainnya dilakukan oleh Burns et al. (2009) tentang kesehatan mental kaum muda di Amerika Serikat serta peran yang dimainkan internet dalam mengurangi stigma dan mendorong pencarian bantuan. Hasil penelitian tersebut menunjukkan adanya peran sebuah layanan internet yang berbasis Australia dalam mereduksi stigma dan meningkatkan bantuan bagi para pemuda Amerika yang berusia 16-25 tahun dan mengalami kesulitan kesehatan mental.

Penelitian lain mengenai peran potensial media sosial dalam mendukung individu dengan kondisi masalah kesehatan mental khususnya pada Twitter yang merupakan media untuk komunikasi antarpribadi oleh individu dengan pengalaman gangguan mental dan kemungkinan sumber umpan balik untuk penyedia layanan kesehatan mental yang dilakukan oleh Shepherd et al. (2015). Hasil dari penelitian tersebut menunjukkan kegunaan media sosial online sebagai ruang diskursif yang memungkinkan individu dengan pengalaman gangguan mental untuk berbagi informasi dan mengembangkan pemahaman serta menjadi media yang memiliki feedback untuk penyedia layanan kesehatan mental (Shepherd et al., 2015). Adapun persamaan penelitian terdahulu dengan penelitian ini terletak pada fokus penelitian yang melihat peran media sosial serta kaitannya dengan stigma. Perbedaan penelitian terdahulu dengan penelitian ini terletak pada stigma yang dilihat bukanlah stigma pada penyimpangan kesehatan mental.

\section{Media Sosial}

Penelitian ini menganalisis mengenai stigma-stigma yang ada tentang kebudayaan Dayak serta peran media sosial "Ruang Dayak" dalam mereduksi stigma kebudayaan Dayak. Adapun media sosial "Ruang Dayak" yang akan diteliti mencakup media sosial jenis mikroblog dan jejaring sosial, yaitu Twitter, Facebook dan Instagram. Sosiawan (2011) menyatakan bahwa situs jejaring sosial juga mampu memberikan dukungan emosional pada pemilik akun. Hal ini dapat saja dipandang sebagai peluang ataupun potensi untuk mengurangi stigma kebudayaan Dayak dengan cara menyentuh sisi emosional para followers. Secara general penelitian ini menganalisis peran media sosial "Ruang Dayak" dalam mereduksi stigma tentang kebudayaan Dayak. Peneliti juga melihat peran media sosial "Ruang Dayak" dalam membangun struktur sosial, menjadi media yang interaktif, menciptakan bentuk-bentuk baru hubungan multikultural, menyebarkan unsur-unsur kebudayaan dari individu yang satu ke individu yanglainsertamenyebarkanpenemuan barudalam bidang ilmu pengetahuan ke masyarakat luas. 


\section{Co-Cultural Theory}

Teori Co-Cultural dasarnya mengacu pada adanya hierarki dalam masyarakat yang mengistimewakan kelompok tertentu. Hierarki tersebut memiliki kelompok yang disebut dengan kelompok dominan. Kelompok dominan tersebut membentuk sistem komunikasi untuk menjaga anggota kelompok budaya underrepresented tetap di luar sekat budaya dominan (Nurwahid \& Rahardjo, 2017). Fokus dari teori ini yaitu memberikan sebuah kerangka di mana para anggota underrepresented menegosiasikan usaha-usaha untuk menyampaikan suara diam mereka dalam struktur masyarakat dominan (L. S. S. Utami, 2015). Kelompok dominan dalam penelitian ini mengacu pada kelompok budaya non-Dayak. Kelompok underrepresented mengacu pada kelompok budaya Dayak. Strategi komunikasi yang digunakan oleh kelompok pendamping meliputi asimilasi dengan menjadi bagian dari kultur dominan, melakukan akomodasi atau berusaha agar para anggota kelompok dominan dapat menerima para anggota kelompok underrepresented, serta separasi atau memilih menolak kemungkinan adanya ikatan bersama dengan para anggota kelompok dominan (Littlejohn \& Foss, 2012). Masalah komunikasi sering muncul ketika sebuah kelompok budaya gagal dipahami oleh lingkungan sekitar yang lebih luas. Hal tersebut menyebabkan Mark Orbe juga merumuskan ada tiga pendekatan yang dilakukan kelompok pendamping dalam berinteraksi dengan kelompok budaya dominan (Nurwahid \& Rahardjo, 2017), yaitu: 1) pendekatan nonassertive yang mengedepankan kebutuhan orang lain yang bersifat non-konfrontatif serta cenderung memperlambat komunikasi; 2) pendekatan assertive yang mengacu pada bagaimana kelompok budaya underrepresented berkomunikasi dengan ekspresif serta memperhitungkan kepentingan diri sendiri dan orang lain; dan 3) pendekatan agresif mengacu pada kelompok budaya underrepresented secara gamblang mempromosikan diri meski terkadang merampas kepentingan orang lain.

\section{Stigma}

Peneliti mengidentifikasi stigma yang ada terkait kebudayaan Dayak dan mengklasifikasikannya ke dalam lima jenis stigma. Stigma merupakan bentuk prasangka yang mendiskreditkan atau menolak seseorang atau kelompok karena dianggap berbeda dengan diri kebanyakan orang (Maharani, 2017). Terdapat lima jenis stigma (Suhanda, 2017), yaitu: 1) label atau cap yang mengacu pada saat seseorang dicap atau dijuluki dengan sebutan tertentu oleh masyarakat; 2) prasangka atau sikap negatif terhadap anggota kelompok tertentu yang semata-mata keanggotaan dalam kelompok tertentu; 3) stereotip yang mengacu pada kecenderungan seseorang atau kelompok orang untuk menampilkan gambar atau gagasan yang keliru (false idea) mengenai kelompok orang lain yang bersifat menghina dan merendakan secara fisk maupun tingkah laku; 4) diskriminasi atau perlakuan yang tidak seimbang dan tidak adil terhadap perorangan atau kelompok berdasarkan ras, suku, agama dan golongan; dan 5) pengucilan atau perlakuan terhadap seseorang atau kelompok yang menyebabkan rasa terasing, ditolak, dijauhi dari pergaulan sehingga merasa tidak diterima lagi oleh orang-orang sekitarnya. Hal ini sesuai dengan konsep stigma menurut Goffman mengacu pada tanda negatif yang diberikan dan melekat di diri seseorang dari pihak eksternal (Rahman \& Syafiq, 2017).

Ada beberapa pendekatan yang dirumuskan oleh Corrigan dan Penn dalam pengurangan stigma yang berfokus pada tiga cabang pendekatan yaitu protes, pendidikan dan kontak sosial (Haimson et al., 2012). Protes mencakup berbicara atau mengutarakan sikap menentang tindakan diskriminasi terhadap kebudayaan Dayak. Pendidikan mencakup juga tindakan penyajian fakta tentang kebudayaan Dayak yang berefek pada pengurangan stigma. Kontak sosial mengacu pada mempromosikan kontak antarpribadi antara publik dan pihak dengan yang dikenakan stigma (Haimson et al., 2012). 
Berdasarkan latar belakang dan kajian pustaka, penelitian ini bertujuan untuk menganalisis peran media sosial dalam mereduksi stigma tentang kebudayaan Dayak.

\section{Metode Penelitian}

Penelitian ini merupakan suatu penelitian eksplanatif kualitatif. Menurut Moleong (2017), penelitian kualitatif merupakan pengumpulan data pada suatu latar alamiah, dengan menggunakan metode alamiah, dan dilakukan oleh orang atau peneliti yang tertarik secara alamiah. Penelitian eksplanatif bertujuan untuk mencari sebab akibat antara dua atau lebih konsep yang akan diteliti (Sugiyono, 2017). Penelitian ini merupakan penelitian eksplanatif kualitatif karena berhubungan dengan persepsi maupun pendapat mengenai peran media sosial dalam mereduksi stigma kebudayaan Dayak yang tidak dapat diukur dengan angka, serta bertujuan untuk mengetahui sebab dari munculnya stigma tentang kebudayaan Dayak.

Creswell(2011)mengatakanbahwapenelitian studi kasus merupakan strategi penelitian di mana di dalamnya peneliti menyelidiki secara cermat suatu program, peristiwa, aktivitas, proses, atau sekelompok individu. Penelitian ini merupakan penelitian studi kasus tunggal yang meneliti peran media sosial "Ruang Dayak" serta stigma kebudayaan Dayak. Objek penelitian ini mencakup media sosial "Ruang Dayak" yaitu Instagram, Twitter dan Facebook. Subyek penelitian ini mencakup founder akun "Ruang Dayak" serta followers (Dayak maupun non-Dayak) dari media sosial "Ruang Dayak".

Cakupan kasus yang diteliti meliputi mencari tahu mengenai peran "Ruang Dayak" dalam mereduksi stigma kebudayaan Dayak. Teknik pengumpulan data menggunakan data primer maupun data sekunder. Data primer diperoleh melalui wawancara mendalam dengan pihak founder akun "Ruang Dayak" serta followers (Dayak maupun non-Dayak) dari media sosial "Ruang Dayak" (Facebook, Instagram dan
Twitter) masing-masing satu orang dari tiap platform media sosial. xInformasi mengenai informan dipaparkan pada Tabel 1 berikut ini:

Tabel 1 memaparkan bahwa para informan mengetahui tentang media sosial "Ruang Dayak" dari teman-teman yang juga adalah orang Dayak. AAE yang merupakan orang Dayak juga mengetahui "Ruang Dayak" dari rekan-rekan satu forum kedaerahan yang diikutinya. Media sosial yang diikuti serta intensitas mengakses media sosial "Ruang Dayak" oleh para informan berbeda-beda karena dipengaruhi oleh pola intensitas penggunaan media sosial para informan yang berbedabeda. Data sekunder penelitian ini meliputi buku, artikel, foto, jurnal, ataupun dokumendokumen lain yang memuat tentang kebudayaan Dayak serta stigma pada kebudayaan Dayak.

Teknik analisis data yang digunakan dalam penelitian ini terdiri dari tiga tahap yang dirumuskan oleh Miles dan Huberman. Adapun tiga tahap tersebut adalah (Sugiyono, 2015): 1) Reduksi data merupakan proses data-data yang telah terkumpul kemudian diseleksi, dirangkum dan disesuaikan dengan fokus penelitian. Data penelitian ini yang terkumpul dari sumber primer maupu sekunder kemudian diseleksi sesuai kebutuhan, seperti data tentang media sosial "Ruang Dayak", stigma kebudayaan Dayak, serta peran media sosial "Ruang Dayak" dalam mengurangi stigma kebudayaan Dayak;

Tabel 1 Informan dan Media Sosial "Ruang Dayak"

\begin{tabular}{lllll}
\hline Inisial & $\begin{array}{c}\text { Media sosial } \\
\text { "Ruang Dayak" } \\
\text { yang diikuti }\end{array}$ & $\begin{array}{c}\text { Tahun } \\
\text { mengikuti } \\
\text { "Ruang Dayak" }\end{array}$ & $\begin{array}{c}\text { Sumber informasi } \\
\text { tentang "Ruang } \\
\text { Dayak" }\end{array}$ & $\begin{array}{c}\text { Intensitas } \\
\text { mengakses } \\
\text { "Ruang } \\
\text { Dayak" }\end{array}$ \\
\hline MFHL & Instagram & 2016 & Teman & Tinggi \\
YB & Twitter & 2017 & Teman & Sedang \\
CDLT & Facebook & 2018 & Teman & Sedang \\
AAE & Instagram & 2016 & Teman & Tinggi
\end{tabular}

Sumber: Hasil olahan penelitian (2019) 
2) Penyajian data merupakan sekumpulan informasi yang menggambarkan penelitian secara menyeluruh dan terperinci. Pada penelitian ini, data disajikan lewat kalimat yang disusun secara sistematis; dan 3) Penarikan kesimpulan atau verifikasi dilakukan guna mencari arti, makna, penjelasan yang dilakukan terhadap data yang telah dianalisis dan dikaitkan dengan teori penelitian. Kesimpulan ini disusun dalam bentuk pernyataan singkat tentang peran media sosial dalam mengurangi stigma kebudayaan Dayak.

\section{Hasil Penelitian Dan Pembahasan}

Guna memperoleh data primer untuk penelitian ini peneliti telah melakukan wawancara dengan founder "Ruang Dayak". Setelah mewawancarai founder "Ruang Dayak" peneliti kemudian mewawancarai para follower "Ruang Dayak" untuk melihat tercapai atau tidaknya upaya dari media sosial "Ruang Dayak" dalam mereduksi stigma kebudayaan Dayak.

\section{Pemahaman tentang Kebudayaan Dayak}

Peneliti menanyakan beberapa pertanyaan kepada founder media sosial "Ruang Dayak" terkait dengan pandangan mengenai kebudayaan secara luas dan kebudayaan Dayak.

"Sangat istimewa. Dengan keberagaman budaya, Indonesia di kenal sangat kaya akan budaya dan tradisi. Keberagaman budaya sama dengan keberagaman keyakinan, dengan adanya perbedaan, kita bisa saling memahami dan mengerti karakter, cara, bahasa satu sama lain (MDP, wawancara 23 Maret 2019)."

Bagi founder "Ruang Dayak" keberagaman budaya merupakan suatu kekayaan yang dimiliki oleh Indonesia. Keberagaman budaya yang ada di Indonesia dapat dilihat dari banyaknya suku yang ada di Indonesia. MDP yang menganggap keberagaman budaya di Indonesia sebagai sesuatu yang istimewa menjadikan dirinya pribadi yang tidak memandang rendah budaya satu dengan lainnya sehingga kesulitan dalam berkomunikasi dengan pihak yang memiliki kebudayaan yang berbeda dengannya tidak dirasakannya. Founder "Ruang Dayak" tersebut menambahkan bahwa di media sosial semuanya dapat memaparkan aspirasi dengan bebas dan setara sehingga tidak ada kelompok budaya yang dominan ataupun underrepresented di dalam media sosial.

"Ruang Dayak" dibentuk berlandaskan pada keresahan dan kekecewaan MDP tentang masih banyak orang yang tidak mengetahui tentang kebudayaan Dayak dan mengetahui informasi yang kurang tepat tentang kebudayaan Dayak. Adapun pandangan-pandangan negatif tentang kebudayaan Dayak yang diketahui oleh MDP dan pemicu munculnya pandangan tersebut adalah sebagai berikut: “....perang antar suku, Dayak dan Madura tahun berapa sih 96 akhir kah yaaa... Dayak makan orang lah, penggal kepala lah, suku yang kebal dan beringas (membunuh) (MDP, wawancara 23 Maret 2019)." MDP menyatakan bahwa seseorang ada yang bertanya atau berpandangan negatif tentang kebudayaan Dayak, maka dirinya secara personal berusaha menjelaskan tentang kondisi masyarakat Dayak saat ini yang juga mengikuti perkembangan zaman. Marselinus selaku founder "Ruang Dayak" akhirnya membentuk "Ruang Dayak" agar usahanya untuk menjelaskan tentang kondisi masyarakat Dayak yang juga mengikuti perkembangan zaman tersebut dapat lebih menjangkau masyarakat non-Dayak secara luas dengan memanfaatkan media sosial.

\section{Paparan Media Sosial "Ruang Dayak"}

Peneliti memperoleh jawaban atas beberapa pertanyaan terkait paparan media sosial "Ruang Dayak" dari para informan yang merupakan follower "Ruang Dayak" (Tabel 2).

Informasi yang dicari oleh para informan di media sosial "Ruang Dayak" cukup beragam. Informasi tentang ritual adat, event kebudayaan, musik dan tari menjadi hal-hal yang dicari para informan di media sosial "Ruang Dayak". Baik dalam bentuk foto maupun video, para 
informan terbiasa untuk membaca caption yang mengandung informasi lebih lengkap yang menjelaskan tentang foto ataupun video yang diunggah oleh "Ruang Dayak" di media sosialnya. Hal ini menjadi sesuatu yang dipertahankan oleh "Ruang Dayak" guna menjaga kualitas dan kelengkapan informasi yang diterima oleh para follower media sosial "Ruang Dayak".

Secara general, keempat informan menganggap media sosial "Ruang Dayak" merupakan media sosial yang informatif. Hal ini disebabkan media sosial "Ruang Dayak" memberikan informasi-informasi yang dibutuhkan. Informan keempat menambahkan bahwa media sosial "Ruang Dayak" memberikan informasi tentang Dayak di masa lalu maupun di masa kini. Informasi tentang Dayak di masa lalu mengacu pada informasi yang menyangkut ritual adat sedangkan informasi tentang Dayak di masa kini tentang perkembangan musik kreasi dan karya-karya anak muda Dayak yang diunggah oleh "Ruang Dayak". Hal ini selaras adanya dengan yang dipaparkan oleh MDP bahwa "Ruang Dayak" mengupayakan agar media sosial "Ruang Dayak" hadir sebagai media sosial yang memberikan informasi tentang kebudayaan Dayak bagi para follower-nya. Adapun upaya tersebut dihadirkan dengan menjaga kualitas konten yang sesuai dengan kriteria standar yang telah dirancang oleh "Ruang Dayak" salah satunya berupa nilai guna konten yang bersifat informatif dan mengandung informasi yang lengkap. Informan kedua mengkritisi dan memberikan masukan terkait akun Twitter "Ruang Dayak" yang terkesan hanya seperti media sosial tempat berbagi tautan semata dan kurang memaksimalkan fitur dan fasilitas yang ada di platform media sosial tersebut. Kurang maksimalnya penanganan media sosial "Ruang Dayak" dikarenakan semua media sosial "Ruang

Tabel 2 Paparan Media Sosial "Ruang Dayak" menurut Informan

\begin{tabular}{|c|c|c|c|}
\hline Inisial & $\begin{array}{c}\text { Media Sosial } \\
\text { "Ruang Dayak" } \\
\text { yang diikuti }\end{array}$ & $\begin{array}{l}\text { Informasi yang dicari di media } \\
\text { sosial "Ruang Dayak" }\end{array}$ & $\begin{array}{l}\text { Informasi yang diperoleh setelah } \\
\text { terpaparmedia sosial "Ruang Dayal" }\end{array}$ \\
\hline MFHL & Instagram & $\begin{array}{l}\text { "Informasi tentang ritual-ritual } \\
\text { adatnya sih mbak. Mau } \\
\text { bentulknya foto ataupun video } \\
\text { ya, yang jelas saya tetap baca } \\
\text { captionnya buat penjelasan yang } \\
\text { lebih detail lagi" }\end{array}$ & $\begin{array}{l}\text { "....informasi tentang Dayak yang } \\
\text { belum banyak orang tahu. Contohnya } \\
\text { seperti makanan mereka, gaya hidup } \\
\text { mereka, kayak kebiasaan mereka yang } \\
\text { pasti ada di akun "Ruang Dayak". }\end{array}$ \\
\hline YB & Twitter & $\begin{array}{l}\text { "Ya apapun sih mbak tentang } \\
\text { Dayak. Mau itu event, info } \\
\text { tentang ritualnya, atau yang lain } \\
\text { juga." }\end{array}$ & $\begin{array}{l}\text { "Memang "Ruang Dayak" juga sangat } \\
\text { informatif.... dan juga untuk mengenal } \\
\text { budaya Dayak yang saya kurang tahu } \\
\text { itu jadi lebih baik." }\end{array}$ \\
\hline CDLT & Facebook & $\begin{array}{l}\text { "Kalau saya sih nyari info soal } \\
\text { event-event yang ada dan bisa } \\
\text { saya kunjungi. Sama saya juga } \\
\text { liat-liat cover lagu atau video } \\
\text { tari-tarian Dayak." }\end{array}$ & $\begin{array}{l}\text { "Dan dari "Ruang Dayak" ini saya } \\
\text { suka sih karena ada lagu-lagu pop } \\
\text { kekinian yang juga di-cover dengan } \\
\text { menggunakan alat musik tradisional } \\
\text { mereka gitu." }\end{array}$ \\
\hline $\mathrm{AAE}$ & Instagram & $\begin{array}{l}\text { "Informasi tentang Dayak yang } \\
\text { belum saya tahu. Cover-cover } \\
\text { lagu pake Sape', video-video } \\
\text { ritual adat atau info apa sih yang } \\
\text { terbaru tentang Dayak. Gitu sih } \\
\text { mbak." }\end{array}$ & $\begin{array}{l}\text { "...saya dapat informasi kayak } \\
\text { kegiatan acara-acara, pesta adat gawai } \\
\text { Dayak. dan banyak tahu soal ritual } \\
\text { adat lainnya." }\end{array}$ \\
\hline
\end{tabular}

Sumber: Hasil olahan penelitian (2019) 
Dayak" yang masih bersifat independen sehingga secara keseluruhan masih ditangani oleh founder dan hanya dibantu oleh dua orang kerabat lainnya yaitu admin non-aktif dan adik sang founder.

\section{Peran Media Sosial "Ruang Dayak"}

"Ruang Dayak" hadir dengan pesan utama untuk memublikasikan agar apapun informasi tentang budaya Dayak dapat dibagikan ke semua hingga dunia mengenal tentang suku budaya Dayak. Menularkan semangat melestarikan budaya dengan memanfaatkan teknologi, merangsang secara tidak sengaja individu-individu untuk aktif berbagi informasi tentang kebudayaan Dayak serta hadirnya relasi antar budaya dengan akun media sosial berkonten kebudayaan lainnya menjadi dampak dari hadirnya "Ruang Dayak" yang dilihat oleh founder "Ruang Dayak".

Terkait dengan reduksi stigma kebudayaan Dayak, media sosial "Ruang Dayak" lebih mengambil cara untuk tetap berfokus pada memberikan informasi tentang kebudayaan Dayak dibanding dengan menjawab secara to-thepoint tiap stigma yang ada tentang kebudayaan Dayak. Pihak "Ruang Dayak" memilih cara untuk fokus pada tujuan dan dasar dibentuknya "Ruang Dayak". Hal tersebut memerlukan waktu panjang untuk mengubah pandangan dan pikiran orang lain tentang kebudayaan Dayak. Founder "Ruang Dayak" berharap agar "Ruang Dayak" dapat menjalin kerjasama dengan lembaga-lembaga resmi dan sekiranya media sosial "Ruang Dayak" dapat mengubah pandangan negatif tentang Dayak yang ada di benak orang non-Dayak karena telah mendapat informasi yang cukup dan dapat dipercaya tentang kebudayaan Dayak dari "Ruang Dayak".

Berdasarkan hasil wawancara, para informan menjawab bahwa pandangan informan tentang kebudayaan Dayak setelah berinteraksi dengan "Ruang Dayak", terlihat pada tabel 3.

Dua dari tiga informan penelitian ini menyatakan bahwa media sosial "Ruang Dayak" memiliki peran sebagai media sosial yang memberikan informasi tentang kebudayaan Dayak sehingga membantu meluruskan pandangan yang salah di benak informan tentang kebudayaan Dayak. Hal ini selaras adanya dengan pemaparan MDP yang adalah founder "Ruang Dayak" yang memaparkan bahwa tujuan dibentuknya "Ruang Dayak" untuk memberikan informasi tentang Dayak baik bagi non-Dayak maupun Dayak dan menjadi media promosi kebudayaan Dayak ke ranah yang lebih luas agar lebih dikenal oleh masyarakat.

Informan ketiga menyatakan informasi saja masih belum cukup untuk mengubah pandangnya. Hal ini didukung dengan kenyataan bahwa informan pertama dan informan kedua telah mengalami kontak langsung atau berinteraksi secara langsung dengan orang Dayak selain media sosial "Ruang Dayak" sehingga terjadi perubahan pandangan tentang kebudayaan Dayak yang tadinya negatif menjadi positif. Berbeda dengan informan ketiga yang belum mengalami kontak langsung atau berinteraksi secara langsung dengan orang Dayak yang baginya dapat mengubah pandangan negatifnya tentang kebudayaan Dayak.

Kebudayaan Dayak merupakan budaya underrepresented dari budaya lainnya yang lebih dominan di Indonesia. "Ruang Dayak" juga menjadi media sosial berkonten kebudayaan yang secara gamblang mempromosikan diri. Berbeda dengan pendekatan agresif underrepresented yang dirumusan Mark Orbe pada teori CoCultural, "Ruang Dayak" media sosial berkonten kebudayaan ini berfokus pada tujuannya untuk mempromosikan kebudayaan Dayak dan tidak merampas kepentingan orang lain. Informan memaparkan bahwa media sosial memungkinkan meleburnya batasan antara kelompok dominan dan kelompok underrepresented. Kelompok tersebut menjadi tidak ada yang dominan ataupun underrepresented karena semua kelompok dapat memberikan aspirasinya secara bebas tanpa merampas kepentingan 
Tabel 3 Peran Media Sosial "Ruang Dayak" menurut Informan

\begin{tabular}{|c|c|c|}
\hline Inisial & $\begin{array}{l}\text { Media Sosial "Ruang } \\
\text { Dayak" yang diikuti }\end{array}$ & $\begin{array}{c}\text { Pandangan tentang Kebudayaan Dayak setelah } \\
\text { berinteraksi dengan "Ruang Dayak" }\end{array}$ \\
\hline MFHL & Instagram & $\begin{array}{l}\text { "Yang tadinya saya kira Dayak itu begini } \\
\text { begitu ternyata setelah liat akun "Ruang } \\
\text { Dayak" saya jadi tahu info yang sebenarnya } \\
\text { tentang Dayak baik orangnya, terlebih lagi soal } \\
\text { budayanya." }\end{array}$ \\
\hline YB & Twitter & $\begin{array}{l}\text { "Dari "Ruang Dayak" seperti yang saya } \\
\text { katakan sebelumnya ya saya jadi lebih paham } \\
\text { ada beberapa hal yang dijelaskan tentang } \\
\text { budaya Dayak membuat hal-hal yang selama } \\
\text { ini hanya jadi pertanyaan bagi saya" }\end{array}$ \\
\hline CDLT & Facebook & $\begin{array}{l}\text { "Ya "Ruang Dayak" bagi saya cukup sekedar } \\
\text { pemberi informasi, hanya saja itu belum cukup } \\
\text { untuk mengubah pandangan saya karena saya } \\
\text { orang yang susah berubah pandangannya." }\end{array}$ \\
\hline
\end{tabular}

Sumber: Hasil olahan penelitian (2019)

orang lain. Penelitian ini menghasilkan klasifikasi stigma kebudayaan Dayak (tabel 4).

Tabel 4 menunjukkan data terkait stigmastigma yang masih melekat dengan kebudayaan Dayak. Hasil penelitian menyatakan bahwa Dayak memakan manusia, kebudayaan Dayak memenggal kepala orang, Dayak merupakan suku yang kebal dan beringas, masyarakat Dayak yang biasa dengan budaya bertato. Kebudayaan Dayak juga dianggap identik dengan hal-hal mistis yang menakutkan dan suku pedalaman yang kasar dan suka mabukmabukan. Pandangan negatif atau stigma tentang kebudayaan Dayak muncul karena minimnya pengetahuan tentang Dayak, belum melakukan kontak langsung dengan orang suku Dayak, dan hanya mempercayai stigma tentang Dayak berdasarkan apa yang banyak dibicarakan secara negatif oleh orang non-Dayak tentang kebudayaan Dayak. Pandangan tersebut muncul dipicu dengan adanya kerusuhan antaretnis Dayak dan Madura sekitar tahun 1996 di Kalimantan.

Stigma tentang kebudayaan Dayak didominasi pada tiga jenis stigma, yaitu label, prasangka dan stereotip. Stigma yang tergolong pada label atau cap mengacu pada kebudayaan Dayak sebagai suku yang kebal dan beringas, pedalaman, kasar serta suka mabukmabukan. Stigma yang dipaparkan oleh para informan dikategorikan sebagai jenis stigma label, karena label mengacu pada seseorang dicap atau dijuluki dengan sebutan tertentu oleh masyarakat sekitarnya (Suhanda, 2017).

Stigma yang tergolong pada prasangka adalah stigma tentang suku Dayak yang memakan manusia dan kebudayaan Dayak yang identik dengan hal-hal mistis yang menakutkan. Hal ini dikarenakan prasangka mengacu pada sikap negatif terhadap anggota kelompok tertentu yang semata-mata keanggotaan mereka dalam kelompok tertentu (Suhanda, 2017).

Stigma yang tergolong pada jenis stereotip mengacu pada stigma kebudayaan Dayak yang memenggal kepala orang, suku yang kebal dan beringas, biasa dengan budaya bertato, identik dengan hal-hal mistis yang menakutkan, kasar dan suka mabuk-mabukan. Stigma-stigma tersebut dikategorikan sebagai bentuk stereotip karena mengacu pada kecenderungan seseorang atau kelompok orang untuk menampilkan gambar atau gagasan yang keliru (false idea) mengenai kelompok orang lain. Hal ini biasanya bersifat menghina dan merendakan secara fisk maupun tingkah laku (Suhanda, 2017). Juditha dalam 
Tabel 4 Klasifikasi Stigma Kebudayaan Dayak

\begin{tabular}{ll}
\hline \multicolumn{1}{c}{ Stigma Kebudayaan Dayak } & \multicolumn{1}{c}{ Jenis Stigma } \\
\hline Dayak memakan manusia & Prasangka \\
Dayak memenggal kepala orang & Stereotip \\
Suku yang kebal dan beringas & Label \& Stereotip \\
$\begin{array}{l}\text { Masyarakat Dayak yang biasa dengan } \\
\text { budaya bertato }\end{array}$ & Stereotip \\
$\begin{array}{l}\text { Identik dengan hal-hal mistis yang } \\
\text { menakutkan }\end{array}$ & Prasangka \& Stereotip \\
Suku pedalaman & Label \\
Kasar & Label \& Stereotip \\
Suka mabuk-mabukan & Label \& Stereotip \\
\hline
\end{tabular}

Sumber: Wawancara dengan para informan (2019)

penelitiannya juga menjelaskan bahwa stereotip juga generalisasi tentang kelompok orang yang sangat menyederhanakan realitas (Juditha, 2015).

Stigma yang dipaparkan para informan tidak berlanjut menuju separasi dan diskriminasi, melainkan hanya berhenti di tahap menimbulkan stereotip tentang kebudayaan Dayak. Hal ini sedikit berbeda dengan yang dipaparkan Link dan Phelan (Scheid \& Brown, 2010) mengenai stigma terjadi ketika muncul beberapa komponen yang saling berkaitan. Adapun komponen-komponen tersebut mengacu pada proses memberikan label atas perbedaan yang dimiliki oleh individu tersebut. Hal ini disusul dengan kemunculan keyakinan dari budaya yang dimiliki individu terhadap karakteristik individu atau kelompok lain yang dapat menimbulkan stereotip. Komponen selanjutnya mengacu pada menempatkan individu atau kelompok yang telah diberikan label ke dalam kategori yang berbeda, sehingga terjadi separasi. Komponen terakhir mengacu pada individu yang telah diberikan label mengalami diskriminasi.

Adanya catatan historis mengenai perang antaretnik pada tahun 1996 menjadi hal yang memicu terciptanya stigma tentang kebudayaan Dayak. Stigma yang dipaparkan muncul dikarenakan para informan belum memiliki pengetahuan yang cukup banyak tentang Dayak dan kebudayaannya; belum melakukan kontak langsung dengan orang suku Dayak; dan hanya mempercayai stigma tentang Dayak berdasarkan apa yang banyak dibicarakan secara negatif oleh orang non-Dayak tentang kebudayaan Dayak. Hal ini menunjukkan bahwa sebelum terjadinya proses pemberian label seperti yang dinyatakan oleh Link dan Phelan (tahun?), kurangnya pengetahuan seseorang tentang suatu kebudayaan menjadi awal dari terbentuknya stigma kebudayaan Dayak. Hal inilah perlu menjadi perhatian bahwa segala sesuatu harus berlandaskan pada pengetahuan.

Hasil wawancara yang dilakukan bersama founder "Ruang Dayak" serta keempat informan yang merupakan followers akun media sosial "Ruang Dayak" baik itu di Facebook, Twitter, maupun Instagram, peneliti memperoleh data-data yang berkaitan dengan peran media sosial "Ruang Dayak" dan stigma tentang kebudayaan Dayak.

Media sosial "Ruang Dayak" merupakan media yang berisi konten kebudayaan Dayak yang menghadirkan relasi baru dengan kelompok kebudayaan lainnya. Pemanfaatan media sosial juga dapat menularkan semangat dalam melestarikan budaya, berbagi informasi tentang budaya Dayak di tingkat kelompok atau individu, serta memberikan informasi yang cukup. Informasi kebudayaan yang dibagikan di media sosial ini dapat dipercaya oleh khalayak luas, serta bermanfaat menjadi sarana untuk mengapresiasi karya para penggiat seni lokal.

"Ruang Dayak" sebagai salah satu media sosial berkonten kebudayaan merupakan media sosial yang informatif. Hal ini disebabkan media sosial berkonten kebudayaan Dayak tersebut memberikan informasi-informasi yang diperlukan khalayak seperti memberikan informasi tentang Dayak secara menyeluruh baik dari segi tentang ritual, musik, tari, kuliner, dan keindahan alamnya. Kebudayaan dapat 
dijadikan pembenaran dari nilai dan kejadian di masa lalu, saat ini, dan masa depan. Hal ini dilakukan oleh suku Dayak untuk melangsungkan nilai dan budaya kepada seluruh generasi.

"Ruang Dayak" sebagai media sosial berkonten kebudayaan yang menyebarkan informasi tentang kebudayaan Dayak memiliki potensi dalam mereduksi stigma tentang kebudayaan Dayak dengan memberikan pendidikan berupa penyebaran informasi tentang kebudayaan Dayak. Hal ini sejalan dengan yang rumuskan Corrigan dan Penn (tahun) terkait pengurangan stigma berfokus pada tiga cabang pendekatan yaitu protes, pendidikan, dan kontak sosial (Haimson et al., 2012). Pendekatan melalui pendidikan mencakup tindakan penyajian fakta tentang kebudayaan yang berefek pada pengurangan stigma. Pendekatan melalui pendidikan yang menyajikan informasi faktual tentang kondisi stigmatisasi bertujuan untuk mengoreksi kesalahan informasi yang bertentangan dengan sikap dan keyakinan (Science, 2016). Pendekatan ini dampaknya sering kali memudar dengan cepat. Hal ini terbukti dengan pernyataan informan kedua yang menyatakan bahwa hanya mengubah sedikit dari stigma tentang kebudayaan Dayak bahkan informan ketigayang menyatakan tidak berkurang stigmanya tentang kebudayaan Dayak. Kontak sosial masih merupakan cabang pendekatan untuk mereduksi stigma. Para informan juga menyetujui hal tersebut. Sayangnya, pendekatan tersebut belum dapat diakomodir oleh media sosial berkonten kebudayaan yang diteliti pada penelitian ini. Penelitian ini menemukan bahwa penyebab munculnya stigma tersebut karena kurangnya pengetahuan tentang suatu kebudayaan. Minimnya pengetahuan tidak dapat mengubah ataupun mereduksi stigma yang ada di benak seseorang. Pengetahuan dan cukupnya informasi yang dimiliki seseorang menjadi faktor utama yang diupayakan oleh penggiat media sosial dalam berkonten kebudayaan. Kebudayaan harus terus dilestarikan, namun bila sudah memiliki stigma tersendiri harus diberikan informasi positif melalui media sosial. Informasi yang disebarkan Hal ini menjadi perhatian bersama, agar stigma tidak muncul di kalangan budaya lain dan merusak kebudayaan Indonesia.

\section{Simpulan}

Penelitian ini menemukan potensi media sosial sebagai alat mereduksi stigma kebudayaan dalam bentuk mengubah pandangan pihak yang memiliki stigma negatif tentang kebudayaan Dayak. Peran media sosial "Ruang Dayak" meliputi sarana untuk mengapresiasi karya para penggiat seni lokal, mengajarkan atau memberi informasi lebih tentang kebudayaan yang diangkat, memengaruhi perilaku seseorang terhadap suatu kebudayaan, menjalin hubungan dengan orang lain di luar sukunya, menyelesaikan sebuah masalah, mencapai tujuan agar informasi tentang kebudayaan khususnya kebudayaan Dayak lebih dapat dipahami oleh khalayak, menurunkan ketegangan dan menyelesaian konflik yang berupa stigma tentang kebudayaan Dayak yang beredar di khalayak luas, serta menstimulasi minat para followers atau khalayak non-Dayak pada kebudayaan Dayak.

Minimnya ekspos untuk suatu budaya dibanding dengan budaya lainnya di negara yang memiliki keragaman budaya seperti Indonesia menjadikan orang kekurangan informasi dan pengetahuan tentang budaya tertentu. Penelitian ini menunjukkan bahwa kurangnya pengetahuan dan informasi tentang suatu kebudayaan menyebabkan munculnya stigma. Kurangnya pengetahuan kemudian mengarah pada pemberian label dan tahapan proses pembentukan stigma negatif.

Stigma pada kebudayaan Dayak yang muncul karena kurangnya informasi tersebut dijembatani oleh media sosial "Ruang Dayak" dengan menggunakan pendekatan pendidikan dalam wujud penyeberan informasi tentang kebudayaan Dayak yang diunggah di media sosial "Ruang Dayak". Pendekatan pendidikan 
yang dapat diterapkan dalam bentuk penyebaran informasi dilakukan oleh pihak media "Ruang Dayak" dianggap memiliki efek sedikit dan dapat mereduksi stigma, dengan memberi informasi yang cukup dan dapat dipercaya dapat mengatasi munculnya suatu stigma kebudayaan.

Penelitian ini merekomendasikan kepada pengelola akun "Ruang Dayak" agar menggunakan pendekatan pendidikan untuk jangka panjang melalui media sosial tersebut untuk mereduksi stigma kebudayaan yang muncul karena kurangnya informasi. Pendekatan pendidikan diwujudkan antara lain melalui penyebaran informasi yang cepat dan luas melalui media sosial memungkinkan informasiinformasi yang tadinya belum diketahui atau salah dalam dipahami dapat digantikan dengan informasi yang tepat secara cepat. Media sosial yang digunakan untuk mereduksi stigma kebudayaan sebaiknya dikelola secara optimal, aktif, interaktif, dan kreatif.

\section{Daftar Pustaka}

Anggraeni, A. (2018). 7 Fakta Unik tentang Suku Dayak, Bukti Indonesia Luar Biasa Kaya. Idntimes.Com. Diambil dari https:// www.idntimes.com/travel/destination/ ayu-anggraeni/7-fakta-unik-tentang-sukuDayak-bukti-indonesia-luar-biasa-kaya-1 Betton, V., Borschmann, R., Docherty, M., Coleman, S., Brown, M., \& Henderson, C. (2015). The role of social media in reducing stigma and discrimination. The British Journal of Psychiatry, 206(6), 443-444. https://doi.org/10.1192/bjp.bp.114.152835

Bhatasara, S. (2015). Globalization, social policies, and thenationstate. November 2013.

Burns, J. M., Durkin, L. A., \& Nicholas, J. (2009). Mental health of young people in the United States: what role can the internet play in reducing stigma and promoting help seeking?. The Journal of adolescent health: official publication of the Society for
Adolescent Medicine, 45(1), 95-97. https:// doi.org/10.1016/j.jadohealth.2008.12.006 Creswell, J. W. (2011). Research design: Pendekatan kualitatif, kuantitatif, dan mixed (3rd ed.) (Terjemahan Achmad Fawaid). Yogyakarta: Pustaka Pelajar. Pendidikan Vokasi. Darmadi, H. (2016). Dayak Asal-Usul Dan Penyebarannya. SOSIAL HORIZON: Jurnal Pendidikan Sosial, 3(2), 322-340. http://dx.doi.org/10.31571/sosial.v3i2.376 Gieskha.(2018). Fakta MenarikKecantikan Gadis Dayak. Wanita.Me. Diambil dari https:// www.wanita.me/kecantikan-gadis-Dayak/ Haimson, O. L., Ringland, K. E., Simpson, S., \& Wolf, C. T. (2012). Using Depression Analytics to Reduce Stigma via Social Media: Blue Friends. Journal of Social \& Clinical Psychology. Hootsuite. (2018). Digital in 2018 in Southeast Asia. We Are Social. Irawan, Y. K. (2016). Ubah Stigma, Panitia Larang Penjualan Arak Selama Pekan Gawai Dayak. Kompas.Com. Diambil dari https://travel. kompas.com/read/2016/05/11/162000927/ Ubah.Stigma.Panitia.Larang.Penjualan. Arak.Selama.Pekan.Gawai.Dayak Juditha, C. (2015). Stereotip dan Prasangka dalam Konflik Etnis Tionghoa dan Bugis Makassar. Jurnal Ilmu Komunikasi, 12(1), 87-104. https://doi.org/10.24002/jik.v12i1.445 Littlejohn, S., \& Foss, K. (2012). Encyclopedia of Communication Theory. Encyclopedia of Communication Theory. https:// doi.org/10.4135/9781412959384 Maharani, F. (2017). Faktor -Faktor Yang Berhubungan Dengan Stigma Terhadap Orang Dengan HIV dan Aids (Odha). Jurnal Endurance, 2(2), 158-167. https://doi.org/10.22216/jen.v2i2.1300 Moleong, L. J. (2017). Metodologi Penelitian Kualitatif (Revision). Bandung: PT. Remaja Rosdakarya. 
Nasrullah, M. (2017). The Dayak: Close To the Eyes,FarfromTheHeart.Proceedingsof the 1st International Conference on Social Sciences Education - "Multicultural Transformation in Education, Social Sciences and Wetland Environment" (ICSSE), 147, 229-233. https://doi.org/10.2991/icsse-17.2018.53 Nurwahid, A. F., \& Rahardjo, T. (2017). Interaksi Kelompok Punk Dengan Netizen (Kajian Fenomenologi Gerakan, Punk Medsos $^{e e}$ Dalam Situs Direktori Konten Punk). Interaksi Online, 5(3), 1-15. Diakses dari https://ejournal3.undip.ac.id/index. php/interaksi-online/article/view/16560

Pradana, R. P. (2017, September 18). Karolin Nilai Kongres Dayak Internasional Bentuk Diplomasi Cerdas Masyarakat Adat. Tribunnews Online. Diambil dari http:// pontianak.tribunnews.com/2017/07/26/ karolin-nilai-kongres-Dayak-internasionalbentuk-diplomasi-cerdas-masyarakat-adat

Prasetia, A. (2018). Di Bali, Jokowi Bandingkan Jumlah Suku Indonesia dengan Afghanistan. Detik.Com. Diambil dari https://news.detik.com/berita/d-3881502/ di-bali-jokowi-bandingkan-jumlahsuku-indonesia-dengan-afghanistan

Rahman, A. F., \& Syafiq. M. (2017). Motivasi, Stigma dan Coping Stigma pada Perempuan Bercadar. Jurnal Psikologi Teori dan Terapan, 7(2), 103-115. http:// dx.doi.org/10.26740/jptt.v7n2.p103-115

Scheid, T. L., \& Brown, T. N. (2010). A handbook for the study of mental health: Social contexts, theories, and systems. In A handbook for the study of mental health: Social contexts, theories, and systems. https:// doi.org/10.1007/978-94-007-4276-5 25

Science, N. A. of. (2016). Ending discrimination against people with mental and substance use disorders: The evidence for stigma change. In Ending Discrimination Against
People with Mental and Substance Use Disorders: The Evidence for Stigma Change. https://doi.org/10.17226/23442 Shepherd, A., Sanders, C., Doyle, M., \& Shaw, J. (2015). Using social media for support and feedback by mental health service users: Thematic analysis of a twitter conversation. BMC Psychiatry. https:// doi.org/10.1186/s12888-015-0408-y Sosiawan, E. A. (2011). Penggunaan Situs Jejaring Sosial sebagai Media Interaksi dan Komunikasi di Kalangan Mahasiswa. Jurnal Ilmu Komunikasi, 9(3), 60-75. Diambil dari http://jurnal.upnyk.ac.id/ index.php/komunikasi/article/view/3416 Sugiyono. (2015). Metode penelitian pendidikan pendekatan kuantitatif, kualitatif dan pengembangan (Research and development $/ R \& D)$. Bandung : Alfabeta. Sugiyono. (2017). Metode Penelitian Kombinasi (Mixed Methods). In Alfabeta. Suhanda, I. (2017). Stigma Sosial, Bagaimana Mengatasinya? Kompas.Com. Diambil dari https://edukasi.kompas.com/ $\mathrm{read} / 2017 / 09 / 08 / 06270121 / \mathrm{stigma-}$ sosial-bagaimana-mengatasinya? page $=$ all Utami, K. D. (2016). Pemanfaatan Jejaring Sosial Line pada Komunikasi Kelompok Kos Putri "Naomi." Jurnal Ilmu Komunikasi, 14(1), 48-56. Retrieved at http://jurnal.upnyk.ac.id/ index.php/komunikasi/article/view/2119 Utami, L. S. S. (2015). Teori-Teori Adaptasi Antar Budaya. Jurnal Komunikasi, 7(2), 180 -197. http://dx.doi.org/10.24912/jk.v7i2.17 Wibowo,A., Rohmad, Z., Padmaningrum, D., \& Utami, B.W. (2012).Strategi Komunikasi Masyarakat Samin dalam Membangun Ketahanan Pangan Lokal. Jurnal Ilmu Komunikasi, 10(3), 267-271. Diambil dari http://jurnal.upnyk.ac.id/ index.php/komunikasi/article/view/42 